Original Research Paper

\title{
Sistem Penjaminan Mutu Internal Di Satuan Pendidikan Menengah (SMA)
}

\author{
Nyoman Sridana ${ }^{1 *}$, Sudirman Wilian', Dadi Setiadi' ${ }^{1}$. \\ ${ }^{1}$ Program Studi Magister Administrasi Pendidikan, Universitas Mataram
}

*Corresponding Author:

Sridana, Program Studi

Magister Administrasi

Pendidikan, Universitas

Mataram, Indonesia;

Email:

sridana60@gmail.com

\begin{abstract}
Abstrak: Tingkat pengetahuan warga sekolah terkait dengan Sisitem Penjaminan Mutu Internal (SPMI) masih pada tingkat rendah yang masih perlu dikembangkan sebelum membentuk sistem penjaminan mutu internal satuan pendidikan. Selain itu pemahaman pendidik terkait standar pendidikan nasional yang sangat berhubungan dengan tugasnya masih pada tingkat cukup sehingga masih perlu peningkatan pemahaman agar bisa melaksananakan proses dan evaluasi sesuai dengan standar. Perlu pengembangan bagi tenaga pendidik dan kependidikan dalam hal pengetahuan dan keterampilan dalam implementasi penjaminan mutu internal melalui tim khusus dari eksternal satuan pendidikan sampai sekolah tersebut siap untuk bisa melaksanakan sistem penjaminan mutu internal. Untuk dapat melakukan penjaminan mutu pendidikan, satuan pendidikan perlu membentuk SPMI sesuai dengan stándar dan aturan yang berlaku Estándar Nasional Pendidikan (SNP) walaupun dilihat dari nilai akreditasi mencapai stándar tertinggi. Dengan demikian diperlukan kajian terkait dengan sistem penjaminan mutu internal di sekolah-sekolah tersebut agar secara bertahap bisa memenuhi SNP atau bahkan melebihinya.
\end{abstract}

Kata Kunci: Sistem Penjaminan Mutu internal (SPMI), Standar Nasional Pendidikan (SNP), Satuan Pendidikan Menengah.

\section{Pendahuluan}

Sistem penjaminan mutu internal merupakan sistem penjaminan mutu yang dilaksanakan di dan oleh satuan pendidikan tertentu dan melibatkan seluruh komponen dalam satuan pendidikan. Secara nasional, mutu pendidikan menengah di Indonesia belum seperti yang diharapkan. Hasil pemetaan mutu pendidikan secara nasional menunjukkan hanya sekitar $16 \%$ satuan pendidikan yang memenuhi standar nasional pendidikan (SNP) (Direktorat Jenderal Pendidikan Dasar dan Menengah. 2016). Sebagian besar satuan pendidikan lain belum memenuhi SNP, bahkan terdapat sejumlah satuan pendidikan yang masih belum memenuhi stándar pelayanan minimal (SPM).

Standar kualitas pendidikan yang ditetapkan oleh pemerintah berbeda dengan standar yang dilaksanakan oleh satuan pendidikan. Standar yang digunakan oleh sebagian besar sekolah jauh di bawah standar yang ditetapkan oleh pemerintah. Akibatnya, kualitas lulusan yang dihasilkan oleh satuan pendidikan tidak memenuhi standar yang ditetapkan pemerintah.

Masih banyak tim pengelola pendidikan yang tidak memahami secara baik makna standar mutu pendidikan. Selain itu, sebagian besar satuan pendidikan belum memiliki kemampuan untuk bisa manjamin segala proses yang dilaksanakan memenuhi standar kualitas. Satuan pendidikan harus mengimplemetasikan penjaminan mutu pendidikan secara baik dan mandiri serta berkelanjutan. Menurut Pemerintah RI (2003) dalam bentuk Undang-undang Nomor 20 Tahun 2003 bahwa Sistem Pendidikan Nasional adalah keseluruhan komponen pendidikan yang saling terkait secara terpadu untuk mencapai tujuan pendidikan nasional. Selain itu, setiap satuan pendidikan diharuskan melakukan penjaminan mutu pendidikan yang bertujuan untuk memenuhi atau melampaui SNP.

Sistem penjaminan mutu internal pendidikan menengah, merupakan suatu kesatuan unsur yang terdiri atas kebijakan dan proses yang terkait pelaksanaan penjaminan mutu pendidikan yang dilaksanakan oleh setiap satuan pendidikan 
menengah untuk menjamin terwujudnya pendidikan bermutu yang memenuhi atau melampaui SNP. Usaha untuk peningkatan dan penjaminan mutu pendidikan adalah tanggung jawab satuan pendidikan. Untuk peningkatan mutu sekolah secara utuh khususnya SMA swasta di Mataram dibutuhkan pendekatan khusus agar seluruh komponen-komponen sekolah secara bersama-sama bisa memiliki budaya mutu.

Untuk dapat melakukan penjaminan mutu pendidikan, satuan pendidikan perlu membentuk SPMI. Berdasarkan studi pendahuluan di SMA swasta di Kota Mataram yang dijadikan sampel menunjukan bahwa di sekolah-sekolah tersebut belum memiliki sistem penjaminan mutu yang baik sesuai dengan stándar dan aturan yang berlaku walaupun dilihat dari nilai akreditasi mencapai stándar tertinggi. Hal tersebut akan berdampak pada mutu lulusan yang tidak bisa memenuhi SNP sementara sejumlah sekolah lain baik negeri maupun swasta sudah bisa melebihi SNP. Dengan demikian diperlukan kajian terkait dengan sistem penjaminan mutu internal di sekolah-sekolah tersebut agar secara bertahap bisa memenuhi SNP atau bahkan melebihinya. Berdasarkan uraian di atas maka perlu dilakukan penelitian tentang sistem penjaminan mutu internal di SMA NW Mataram sebagai dasar untuk penyusunan atau pengembangan program-program mutu di satuan pendidikan tersebut

\section{Metode Pelaksanaan}

Sistem penjaminan mutu pendidikan dasar dan menengah terdiri atas dua komponen yaitu Sistem Penjaminan Mutu Internal (SPMI) dan
Sistem Penjaminan Mutu Eksternal (SPME). Sistem Penjaminan Mutu Internal adalah sistem penjaminan mutu yang dilaksanakan dalam satuan pendidikan dan dijalankan oleh seluruh komponen satuan pendidikan; Sistem Penjaminan Mutu Eksternal yaitu sistem penjaminan mutu yang dilaksanakan oleh pemerintah, pemerintah daerah, lembaga akreditasi dan lembaga standarisasi pendidikan.

Sebelum membahas tetang sistem penjaminan mutu internal (SPMI) di sekolah sampel terlebih dahulu disampaikan tentang pemahaman tenaga pendidik dan kependidikan yang terlibat langsung dalam implementasi SPMI. Hasil menunjukan bahwa pemahaman kepala sekolah tentang sistem penjaminan mutu internal menunjukan skor 2,20 atau pada tingkat kurang, sedangkan tenaga kependidikan lain dengan skor pemahaman 2,85 lebih tinggi dari kepala sekolah tetapi masih pada tingkatan kurang. Sama halnya pemahaman tenaga pendidik terhadap SPMI mencapai skor 2,13 masih pada tingkat kurang. Selain itu pendidik dan tenaga kependidikan belum memahami secara baik tentang konsep dan prinsip, tujuan dan cakupan SPMI satuan pendidikan, hal tersebut penting bagi pelaksana penjaminan mutu internal, karena jika kurang memahami tentang SPMI tersebut pihak pengelola tidak akan bisa melaksanakannya secara maksimal sesuai dengan rohya SPMI. Solusinya seperti yang dikemukakan oleh Lamosi dan Mukonyi (2015) yang merekomendasikan bahwa kepala sekolah memperkuat manajemen kualitas alternatif seperti teacher appraisal, use of internal quality assurance officers by capacity building on requisite knowledge and skills.

SISTEM PENJAMINAN MUTU PENDIDIKAN DASAR DAN MENENGAH

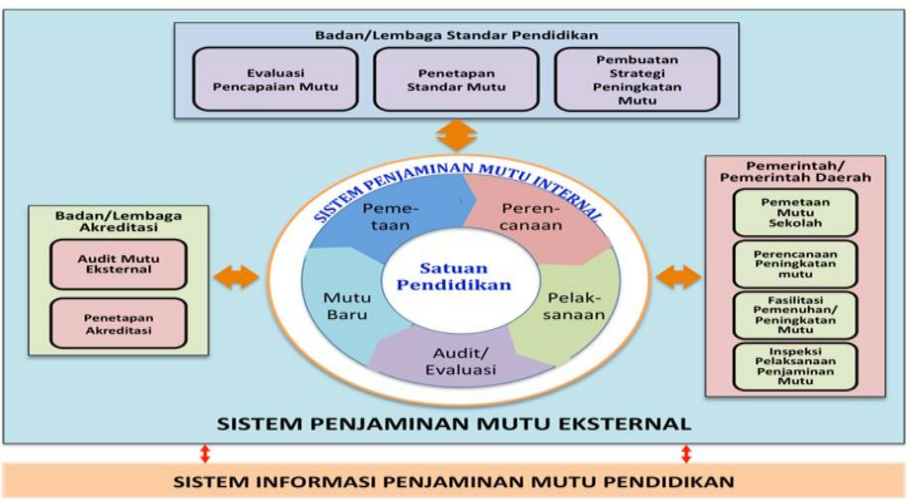

Gambar 1. Sistem Penjaminan Mutu Pendidikan Dasar dan Menengah 
SPMI terkait dengan 8 standar nasional pendidikan dan dengan tugas guru, maka akan terkait terutama dengan standar kompetensi lulusan, standar isi, standar proses, standard evaluasi dan standard pendidik sendiri. Berikut disampaikan tingkat keterpahaman pendidik terhadap standar kompetensi lulusan skor 3,04, Standar Isi skor 3,6, Standar Proses skor 3,0, dan standar Evaluasi skor 3,43. Selain itu yang terkait dengan standar tenaga pendidik mencapai skor 3,8 .
Keterpahaman tersebut baru mencapai tingkat cukup tetapi untuk standar tenaga pendidik mendekati baik. Namun demikian untuk bisa terlaksananya proses dan evaluasi yang sesuai dengan standard maka tingkat pemahaman tenaga pendidik harus di atas baik. Selain itu bahwa guru diterima didasarkan pada pengetahuan konten kurikulum, kualifikasi professional yang telah ditentukan oleh pemerintah (Onuma, dan Okpalanze, 2017).

\section{Penjaminan Mutu}

Suatu mekanisme yang sistematis, terintegrasi dan berkelanjutan untuk
memastikan bahwa seluruh proses pendidikan sesuai dengan standar mutu
dan aturan yang ditetapkan.

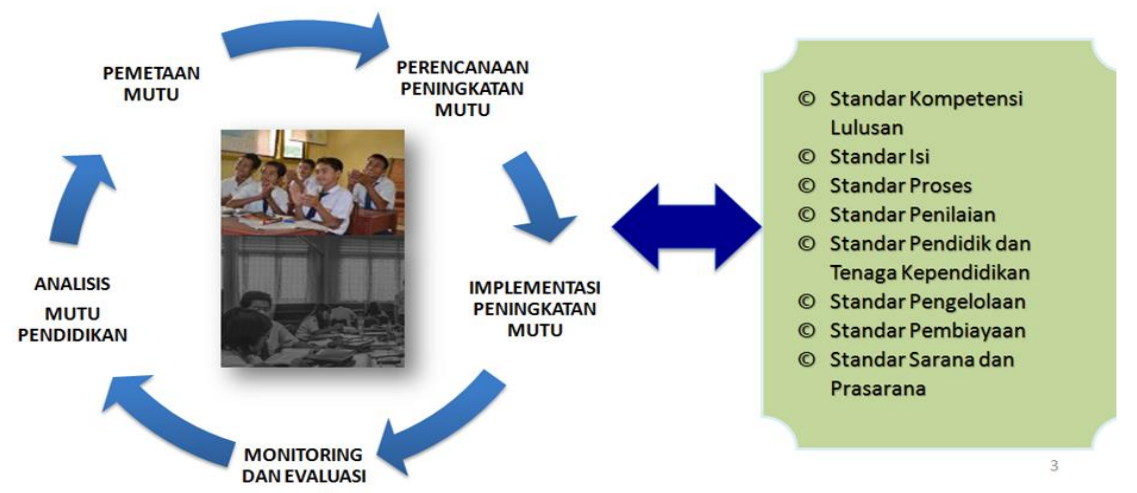

Gambar 2. Penjaminan Mutu

Prinsip Sistem Penjaminan Mutu Internal

Prinsip dari Sistem Penjaminan Mutu Pendidikan adalah mandiri, terstandar, akurat, sistemik dan berkelanjutan, holistik, dan terdokumentasi.

\section{Mandiri}

SPMI dikembangkan dan diimplementasikan secara mandiri oleh setiap satuan pendidikan.

2. Terstandar

SPMI menggunakan Standar Nasional Pendidikan yang ditetapkan oleh Mendikbud dan Standar yang ditetapkan oleh satuan pendidikan bagi satuan pendidikan yang telah memenuhi SNP

3. Akurat

SPMI menggunakan data dan informasi yang akurat

4. Sistemik dan berkelanjutan
SPMI diimplementasikan dengan menggunakan 5 (lima) langkah penjaminan mutu yaitu pemetaan mutu, penyusunan rencana peningkatan mutu, pelaksanaan pemenuhan mutu, audit/evaluasi pemenuhan mutu, dan penetapan standar baru yang dilaksanakan secara berkelanjutan membentuk suatu siklus

5. Holistik

SPMI dilaksanakan terhadap keseluruhan unsur dalam satuan pendidikan yang meliputi organisasi, kebijakan, dan proses-proses yang terkait

4. Terdokumentasi

Seluruh aktivitas dalam pelaksanaan SPMI terdokumentasi dengan baik dalam berbagai dokumen mutu. 


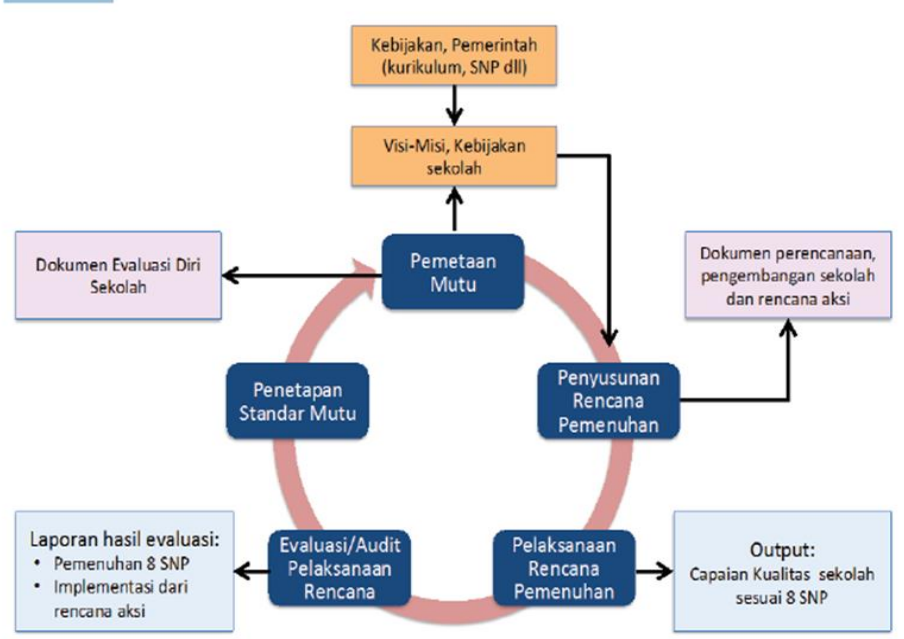

Gambar 3 Siklus Sistem Penjaminan Mutu Internal Pendidikan Dasar dan Menengah

\section{Tujuan SPMI}

Penerapan sistem penjaminan mutu di satuan pendidikan dasar dan menengah bertujuan untuk memastikan bahwa keseluruhan unsure yang meliputi organisasi, kebijakan, dan proses-proses yang terkait di satuan pendidikan dapat berjalan sesuai dengan standar yang ditetapkan untuk menjamin terwujudnya budaya mutu di satuan pendidikan;

\section{Hasil dan Pembahasan}

Sistem penjaminan mutu internal pendidikan dasar dan menengah ini mencakup seluruh aspek penyelenggaraan pendidikan dengan memanfaatkan berbagai sumberdaya untuk mencapai Standar Nasional Pendidikan. SPMI dievaluasi dan dikembangkan secara berkelanjutan oleh setiap satuan pendidikan dasar dan menengah; SPMI ditetapkan oleh satuan pendidikan dan dituangkan dalam pedoman pengelolaan satuan pendidikan serta disosialisasikan kepada pemangku kepentingan satuan pendidikan.

Dalam hubungannya dengan pelaksanaan SPMI di sekolah yang menjadi lokasi penelitian mencakup siklus SPMI yang terdiri dari 5 tahap, Pertama, Pemetaan mutu pendidikan yang dilaksanakan oleh satuan pendidikan berdasarkan Standar Nasional Pendidikan. Pihak tenaga kependidikan dan tenaga pendidik sekolah belum memahami secara detail tentang tahapan pemetanaan mutu pendidikan mulai dari menyusunan instrumen dan pengumpulan data serta analisis data hasil pemetaaan yang akan terkait dengan pembuatan rencana untuk tahap berikutnya dari siklus SPMI. Kegiatan pada tahap ini termasuk evaluasi internal dan bisa dilakukan dengan tahapan Plan, Do, Check dan Act (Nelson, Ehren, dan Godfrey. (2015).

Kedua, Pembuatan rencana peningkatan mutu yang dituangkan dalam Rencana Kerja Sekolah, pihak sekolah tidak mengetahui caranya bagaimana membuat rencana peningkatan mutu yang terkait dengan standar nasional pendidikan. Pembuatan rencana sekolah terkait dengan peningkatan mutu yang harus disusun berdasarkan potret diri sekolah dari kondisi mutu saat evaluasi diri dilakukan, kemudian menyusun sejumlah rencana kerja yang secara keseluruhan berorientasi pada peningkatan mutu proses administrasi dan pembelajaran.

Ketiga, pelaksanaan pemenuhan mutu baik dalam pengelolaan satuan pendidikan maupun proses pembelajaran, pada tahap ini juga pihak pengelola satuan pendidikan belum secara menyeluruh memahami tahap ini dari siklus SPMI, hal ini terkait dengan tingkat pemahaman tahap sebelumnya, oleh karena itu perlu pengkajian yang mendalam terkait dengan implementasi SPMI untuk pemenuhan mutu dalam manajemen satuan pendidikan dan proses pembelajaran secara luas. Hal tersebut memerlukan kebersaman semua warga sekolah untuk bersama-sama melaksananaan 
program sekolah yang berhubungan dengan pemenuhan mutu pendidikan sesuai standar.

\section{Pemetaan Mutu Satuan Pendidikan}

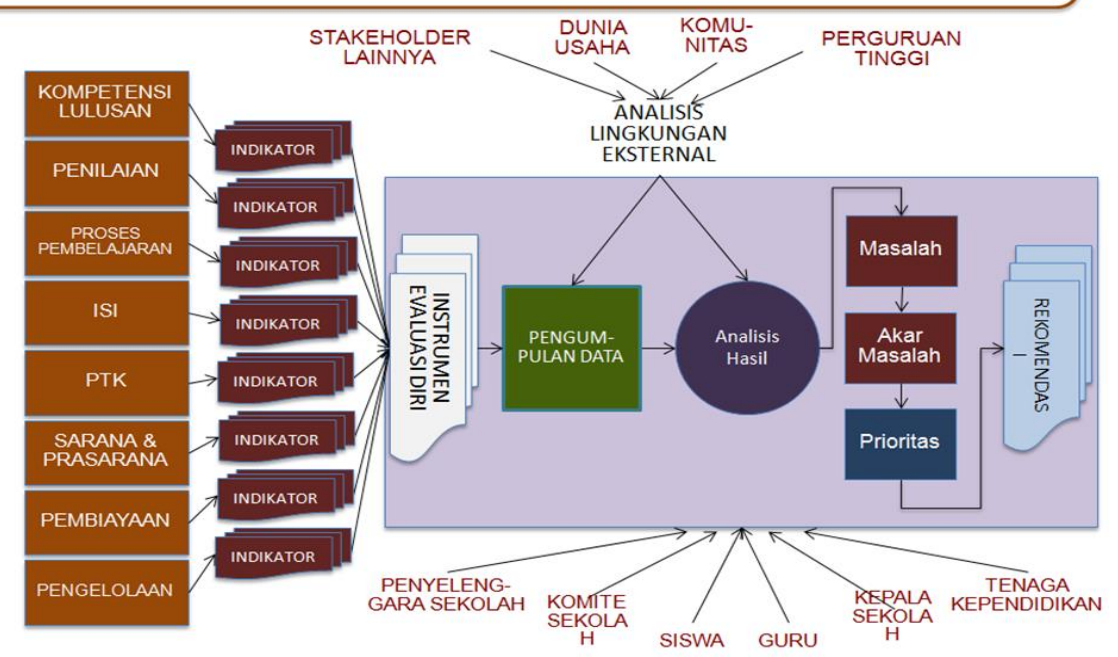

Gmabar 3. Pemetaan mutu pendidikan di satuan Pendidikan

Keempat, Monitoring dan evaluasi proses pelaksanaan pemenuhan mutu yang telah dilakukan, tahap ini pihak sekolah masih membutuhkan pengetahuan secara baik terkait peran dan fungsi monitoring dan evaluasi untuk setiap program pemenuhan mutu, sehingga akan bermanfaat untuk proses selanjutnya tentang penysusunan standar baru dan strategi untuk pencapaian mutu yang telah direncanakan.

Terakhir, Penetapan standar baru dan penyusunan strategi peningkatan mutu berdasarkan hasil monitoring dan evaluasi. Pihak pengelola satuan pendidikan belum memiliki pengetahuan dan pemahaman yang baik tentang penyusunan standar mutu baru termasuk strategi pencapaiannya. Pihak sekolah pun masih harus belajar dan menyiapkan diri terkait dengan tahapan terakhir dari siklus SPMI. Dalam penyusunan program harus secara total holistic process concerned with ensuring integrity of outcomes (Adegbesan, 2011).

Pihak sekolah secara keseluruhan belum memiliki tim khusus yang melaksanakan mengontrol program penjaminan mutu internal, sehingga akan kesulitan dalam meningkatkan status mutu sekolah berdasarkan kualitas pencapaian mutu. Oleh karena itu perlu dimulai dengan merancang SPMI sekolah sesuai dengan kondisi dan daya dukung sumber daya sekolah, tidak perlu membuat target dan indikator yang terlalu tinggi dan sulit dicapai, tetapi program-program mutu tersebut harus sesuai kondisi sekolah, pencapaian mutu dilakukan secara bertahap dan tetap fokus untuk memenuhi SNP secara baik, kemudian jika sudah memiliki daya dukung yang lebih baik maka dilanjutkan untuk menjadi sekolah model bahkan mungkin sekolah rujukan. Namun demikian modal awal adalah komitmen warga sekolah memiliki kemauan untuk maju dan berkualitas melalui kerja sama yang baik dalam berbagai kegiatan program mutu sesuai dikemukakan Praraksa, dkk. (2015) bahwa team work is the vital factor for the schools in order to improve internal quality assurance operational effectiveness since team work supports performance, quality of working life, interaction, collaboration and it is the instrument in organizational development.

Program-program dalam rencana pengembangan sekolah belum secara jelas terkait dengan program mutu dari sitem penjaminan mutu internal sekolah. Hal tersebut disebabkan pihak sekolah belum memiliki sistem penjaminan mutu internal secara baik dan berkelanjutan. Sehingga perlu pengkajian bersama secara menyeluruh menyangkut sumber daya yang dimiliki sekolah untuk bisa lebih meningkatkan kualitas sekolah melalui program-program mutu yang dikelola oleh 
tim system penjaminan mutu internal. Selain itu terdapat sejumlah faktor yang mempengaruhi penjaminan mutu internal berupa four factors of direct effect were administrators' instructional leadership, innovation culture of organization, opened climate of organization and teachers' leadership (Praraksa, dkk. 2015). Juga tergantung pada motivation of teachers is a quality assurance practice in secondary schools (Onuma, dan Okpalanze, 2017) dan quality assurance component aims to enhance teaching and learning as an integral feature of school improvement (Caesar, 2013), termasuk juga the emphasizing understanding and not memorization, the need for more group work and dialogue, restoring the visual-spatial aspects of learning, re-thinking curriculum balance, and re-examining national examination systems (Almadani, Reid, dan Rodrigues, 2011).

Penyusunan program terkait dengan peningkatan mutu perlu memperhatikan sejumlah faktor yang akan berpengaruh sperti disampaikan di atas terkait dengan tenaga pendidik dan kependidikan bahkan termasuk peserta didik yang merupakan faktir yang sangat menentukan keberhasilan peningkatan mutu, sehingga dengan pertimbangan tersebut tingkat kegagalan akan bisa diminimalisir

Dalam konteks implementasi penjaminan mutu internal, penentuan program dan pelaksanaan sperti dikemukakan oleh Uchtiawati, dan Zawawi (2014) bahwa Sekolah melalui mekanisme yang telah ditentukan dapat menentukan tahap-tahap pelaksanaan jaminan mutu sebagai berikut: yaitu: plan (merencanakan), do (melaksanakan), dan melakukan tahap evaluation (mengevaluasi), secara berkelanjutan. Selain itu, diperlukan dukungan adequate facilities and equitable educators will have a significant impact on the implementation of the internal quality assurance system in schools (Darman, Darwin, dan Yusnadi, 2017). Juga untuk lebih meningkatkan penjaminan kualitas dalam hubungannya dengan proses pembelajaran ditunjukan dengan students expressed high satisfaction with the state of learning resources and the competence of the academic staff available to them (Essel1, Boakye-Yiadom, dan Kyeremeh, 2018) dan harus fokus pada economical, technical, and organizational dimensions as main dimensions of feasibility system (Amir, 2015).
Hal lain yang perlu diperhatikan adalah berupa dukungan dari pemerintah should continue to provide adequate infrastructures and facilities in the schools to create a conducive teaching and learning environment for both teachers and the students (Oyewole, 2013), intensified and possibly private participation in the practice should be encouraged (Olufunke, Joseph, dan Adetayo, 2012). Juga memerlukan systems of quality control with regard to the actors, i.e. the stakeholders instead of the institutional configurations: (1) state control and accountability by bureaucratic means and legal regulations, (2) professional control and accountability, and (3) consumer control and accountability (Huber dan Gördel, 2006).

\section{Kesimpulan}

Tingkat pengetahuan warga sekolah terkait dengan SPMI masih pada tingkat rendah yang masih perlu dikembangkan sebelum membentuk sistem penjaminan mutu internal satuan pendidikan. Selain itu pemahaman pendidik terkait standar pendidikan nasional yang sangat berhubungan dengan tugasnya masih pada tingkat cukup sehingga masih perlu peningkatan pemahaman agar bisa melaksananakan proses dan evaluasi sesuai dengan standar. Perlu pengembangan bagi tenaga pendidik dan kependidikan dalam hal pengetahuan dan keterampilan dalam implementasi penjaminan mutu internal melalui tim khusus dari eksternal satuan pendidikan sampai sekolah tersebut siap untuk bisa melaksanakan sistem penjaminan mutu internal.

\section{Daftar Pustaka}

Adegbesan, S. O. 2011. Establishing Quality Assurance in Nigerian Educationsystem: Implication for Educational Manage. Educational Research and Reviews Vol. 6(2), 147-151.

Almadani, K., Reid, N. dan Rodrigues, S. 2011. Quality Assurance: A Pressing Problem For Education in the $21^{\text {st }}$ Century. Problems of Education in the $21^{\text {st }}$ Century. Vol. 32.

Amir, F. 2015. Developing Structure for Management of Quality in Schools: Steps towards Quality Assurance Systems. 
American Journal of Educational Research, Vol. 3, 8, 977-981

Caesar, C. (2013). Framework for Delivery of Quality Education: Examination of quality concepts to inform a framework for improving education quality in St Lucia a member of the Organization of Eastern Caribbean states (OECS). American Academic \& Scholarly Research Journal Vol. (5). 1.

Darman, Darwin, dan Yusnadi. 2017. Implication of Internal Quality Assurance System of Schools Implementation Against the Accreditation rating of State Senior High Schools of Natuna, Riau Island Province. Journal of Research \& Method in Education Volume 7, Issue 5 36-39

Direktorat Jenderal Pendidikan Dasar dan Menengah. 2016a. Pedoman Umum Sistem Penjaminan Mutu Pendidikan Dasar dan Menengah. Jakarta: Direktorat Jenderal Pendidikan Dasar dan Menengah Kementrian Pendidikan dan Kebudayaan.

Direktorat Jenderal Pendidikan Dasar dan Menengah. 2016b. Petunjuk Pelaksanaan Penjaminan Mutu Oleh Satuan Pendidikan. Jakarta: Direktorat Jenderal Pendidikan Dasar dan Menengah Kementrian Pendidikan dan Kebudayaan

Essel1, H. B., Boakye-Yiadom, M. dan Kyeremeh, F. A. 2018.Assessing Students' Experiences of Internal Quality Assurance Practices in Selected Private Higher Education Institutions. International Journal of Science and Research (IJSR). Volume 7 Issue 1.

Huber, S. G. dan Gördel, B. 2006. Quality Assurance in the German School System.European Educational Research Journal, Vol. 5, 3

Nelson, R., Ehren, M. dan Godfrey, D. 2015. Literature Review on Internal Evaluation. London: Institute of Education.,

Olufunke, O. I., Joseph, K. S. dan Adetayo, O. A. 2012. Quality Assurance and Effectiveness of Lagos State Junior Secondary Schools. International Journal of Humanities and Social Science. Vol. 2 No. 15.

Onuma, N. dan Okpalanze, N. P.. 2017. Assessment of Quality Assurance Practices
inSecondary Schools in Enugu State Nigeria. Middle-East Journal of Scientific Research 25 (8): 1695-1714.

Oyewole, B.K. 2013. Repositioning Secondary School Administration for QualityAssurance in Ekiti State, Nigeria. Journal of Management and Sustainability; Vol. 3, 3

Pemerintah Republik Indonesia. 2003. Undangundang No. 20 Tahun 2003 tentang sistem pendidikan nasional. Jakarta : Pemerintah Republik Indonesia.

Praraksa, P., Sroinam, S., Inthusamith, M., dan Pawarinyanon,M. 2015. Model of Factors Influencing Internal Quality Assurance Operational Effectiveness of the Small Sized Primary Schools in Northeast Thailand. Social and Behavioral Sciences $1971586-1590$.

Sugiyono. (2008a). Memahami Penelitian Kualitatif. Bandung: CV Alfabeta.

Sugiyono. (2008b). Metode Penelitian Pendidikan Pendekatan Kuantitatif, Kualitatif, dan RT $\& D$. Bandung : Alfabeta

Uchtiawati, S. dan Zawawi, I . 2014. Penerapan Penjaminan Mutu Pendidikan pada Sekolah Menengah Atas berstandar Internasional. Jurnal Kebijakan dan Pengembangan Pendidikan Vol.2 (1),52-56. 